\title{
Review
}

Journal of Innate

Immunity
J Innate Immun 2011;3:280-288

DOI: $\underline{10.1159 / 000323934}$
Received: October 30, 2010

Accepted after revision: December 24, 2010

Published online: March 12, 2011

\section{Natural Killer Cell Responses to Infections in Early Life}

\author{
Aline Guilmot ${ }^{\mathrm{a}} \quad$ Emmanuel Hermann $^{\mathrm{b}} \quad$ Véronique M. Braud ${ }^{\mathrm{c}} \quad$ Yves Carlier $^{\mathrm{a}}$ \\ Carine Truyens ${ }^{\mathrm{a}}$ \\ aLaboratoire de Parasitologie, Faculté de Médecine, Université Libre de Bruxelles, Brussels, Belgium; \\ bINSERM U1019, CNRS UMR 8204, IPL, Université Lille Nord de France, Lille, and ${ }^{\mathrm{C} C e n t r e ~ N a t i o n a l ~ d e ~ l a ~}$ \\ Recherche Scientifique/Université de Nice-Sophia Antipolis, UMR6097, Valbonne, France
}

\section{Key Words}

Natural killer cell $\cdot$ Early life $\cdot$ Newborn $\cdot$ Infant $\cdot$ Infectious

disease $\cdot$ Immaturity $\cdot$ Virus $\cdot$ Trypanosoma cruzi

\begin{abstract}
Natural killer (NK) cells are an important component of innate immune responses to infectious diseases. They mediate protection by being able to rapidly lyse infected cells and produce cytokines (primarily interferon- $\gamma$ ) that shape innate and adaptive immune responses. This review summarizes current knowledge on the phenotype and functional abilities of NK cells from healthy newborns/infants and on NK cell responses against viral, bacterial and protozoan infections in early life. Interestingly, NK cell blood counts are higher in newborns than in adults but they do not display striking differences in phenotype, except for an increased frequency of expression of the inhibitory CD94/NKG2A receptor. They display some inherent functional defects, mainly a lower cytolytic capacity that may contribute to the immaturity of the neonatal immune system. Changes in circulating levels of NK cells observed during pediatric infections and the ability of NK cells from newborns and children to produce interferon$\gamma$ at the encounter with pathogens indicate that NK cells participate in the immune response to infectious diseases in
\end{abstract}

early life. Unfortunately, information is currently insufficient to assess whether these NK cell responses really contribute to control infections, either vertically transmitted or acquired in infancy.

Copyright $\odot 2011$ S. Karger AG, Basel

Innate immune responses are characterized by their rapidity and are important in limiting the spreading of invading pathogens before adaptive immune response builds up. Natural killer (NK) cells defined as $\mathrm{CD}^{-}$ CD56 $6^{+}$lymphocytes in humans are innate lymphocytes identified in the 1970s through their capacity to kill tumor cell lines in vitro [1]. Since then, innate lymphocytes also encompass particular subsets of B and T lymphocytes (B1-B cells, invariant NK T cells and a subset of $\gamma \delta$ $\mathrm{T}$ cells) expressing germline-encoded antigen receptors [2]. NK cells are rapidly activated by cytokines and contact-dependent signals provided by dendritic cells, monocyte/macrophages and $\mathrm{CD} 4^{+} \mathrm{T}$ cells having encountered pathogens $[3,4]$. Constitutive expression of a complex repertoire of surface receptors enables them to directly sense infected or transformed cells. Activated NK cells mediate protection against pathogens through secretion of cytokines, primarily interferon (IFN)- $\gamma$, that shape in-

\section{KARGER}

Fax +4161306 1234

E-Mail karger@karger.ch

www.karger.com (c) 2011 S. Karger AG, Basel

1662-811X/11/0033-0280\$38.00/0

Accessible online at:

www.karger.com/jin
Dr. Carine Truyens

Laboratoire de Parasitologie, Faculté de Médecine - ULB

808 route de Lennik CP 616

BE-1070 Brussels (Belgium)

Tel. +32 255562 50, E-Mail ctruyens@ulb.ac.be 
nate and adaptive immune responses, as well as destruction of infected cells [5].

As compared to adults, newborns and children present some immunological immaturity, particularly in mounting efficient type 1 immune responses against intracellular pathogens. Several mechanisms account for such deficiency, including deficient pattern recognition receptor signaling, deficient production of interleukin (IL)-12p35 by antigen-presenting cells and of IFN- $\gamma$ by $\mathrm{CD}^{+} \mathrm{T}$ cells [6-8], as well as impaired NK cell functions. This review aims to specifically summarize current knowledge on NK cell responses to infections in early life. In the first part, we will compare the phenotype and the functional abilities of neonatal and adult NK cells, before describing in the second part NK cell responses against viral, bacterial and protozoan infections in early life.

\section{Characterization of NK Cells in Early Life}

\section{Blood Levels of NK Cells}

Levels of circulating NK cells gradually increase with gestational age. Between 25 and 30 weeks of gestation, their count represents one third to half of that found in umbilical cord blood (CB) of full-term newborns [9]. Absolute counts of NK cells in CB of term neonates average $500 / \mathrm{mm}^{3}$, with important variations between individuals (reported levels ranging from 20 to $1,600 \mathrm{NK}$ cells $/ \mathrm{mm}^{3}$ ) [9-12]. CB contains the highest level of NK cells, likely in relation to labor-related stress. NK cell levels then rapidly decrease by 2-3 times in the blood of newborns few days after delivery [11-13] and continue to progressively decline during childhood [11], reaching adult levels (mean of $200 \mathrm{NK}$ cells $/ \mathrm{mm}^{3}$ ) around 5 years of age $[11,12]$.

CD56 ${ }^{\text {bright }} \mathrm{CD} 16^{\text {dim/neg }}$ and $\mathrm{CD} 56^{\text {dim }} \mathrm{CD} 16^{+} \mathrm{NK}$ cells define two functionally distinct mature NK cell subsets. The former secretes high levels of cytokines, is poorly cytotoxic and preferentially homes into lymph nodes, while the latter appears to be mainly cytotoxic effector cells that infiltrate inflamed tissues. The majority (about 90\%) of adult blood NK cells are CD56 ${ }^{\mathrm{dim}}$, while CD $56^{\text {bright }} \mathrm{NK}$ cells make up 75-90 and 50\% of resident NK cells in lymph nodes and the spleen, respectively. They are also numerous in the decidua during gestation $[5,14]$. The proportions of circulating CD56 bright and CD56 $6^{\mathrm{dim}}$ subsets are rather stable over time between birth and adult life, though CD56 ${ }^{\text {bright }} \mathrm{NK}$ cell numbers were reported, by some authors including our group, to be slightly higher in newborns $[12,15,16]$.
Neonatal Repertoire of NK Receptors and Other

Surface Molecules

NK cell function is tightly regulated by activating and inhibitory signals that are delivered by a diverse array of cell surface receptors [5]. These receptors recognize selfligands or microbial molecules expressed on infected cells. The expression of some of them has been studied on CB NK cells. Results are summarized in table 1 . The main features to be put forward are the following. First, the balance between the inhibitory receptor CD94/NK cell group 2 (NKG2)A and the activating receptor CD94/ NKG2C (both binding to the same ubiquitously expressed human leukocyte antigen-E molecule) [17] is much more deviated towards inhibition in neonates than in adults. This is reminiscent of the phenotype of decidual NK cells which are CD94/NKG2A ${ }^{\text {bright }}$ and killer cell immunoglobulin-like receptor (KIR)-, a phenotype associated with NK cell function orientated towards cytokine secretion rather than towards cytotoxicity [14]. Expression of the other activating and inhibitory receptors is variable compared to adults. Since the combination of expression of these receptors may vary between cells, it is not possible to predict the net effect and compare neonatal and adult cells. We can also note that leukocyte immunoglobulin-like receptor (LIR)-1, which binds to classical major histocompatibility complex class I with a broader recognition pattern than KIRs, is very low in CB; adult levels will be reached around 5 years of age $[12,15]$.

CD244 and CD2, belonging to the CD2 family of receptors and binding to CD48 and CD58, respectively, alongside mediating adhesion with target cell, also give costimulatory signals [18]. CD244 expression on NK cells is similar in newborns and adults [12] while the proportion of $\mathrm{CD} 2^{+} \mathrm{NK}$ cells is slightly higher in $\mathrm{CB}$ [19]. Finally, CB NK cells also express adult levels of CD16, the activating Fc $\gamma$ RIII receptor which recognizes IgG and mediates antibody-dependent cellular cytotoxicity (ADCC) $[12,20]$.

\section{Cytotoxic Capacity}

The natural killer cytotoxic (NKC) capacity of CB NK cells, i.e. their capacity to spontaneously and rapidly lyse cognate targets without undergoing previous gene transcription and differentiation, has been extensively studied since the 1980s. Most reports converge to show that NKC capacity is strongly reduced in early life as compared to adults, although some newborns display adultlike cytotoxic function [21]. Indeed, even if NKC was detected in liver cells as early as 9 weeks of gestation [21], it remained at least 3 -fold lower in newborns at term than

J Innate Immun 2011;3:280-288 
Table 1. Surface expression of receptors and adhesins on circulating neonatal and adult NK cells

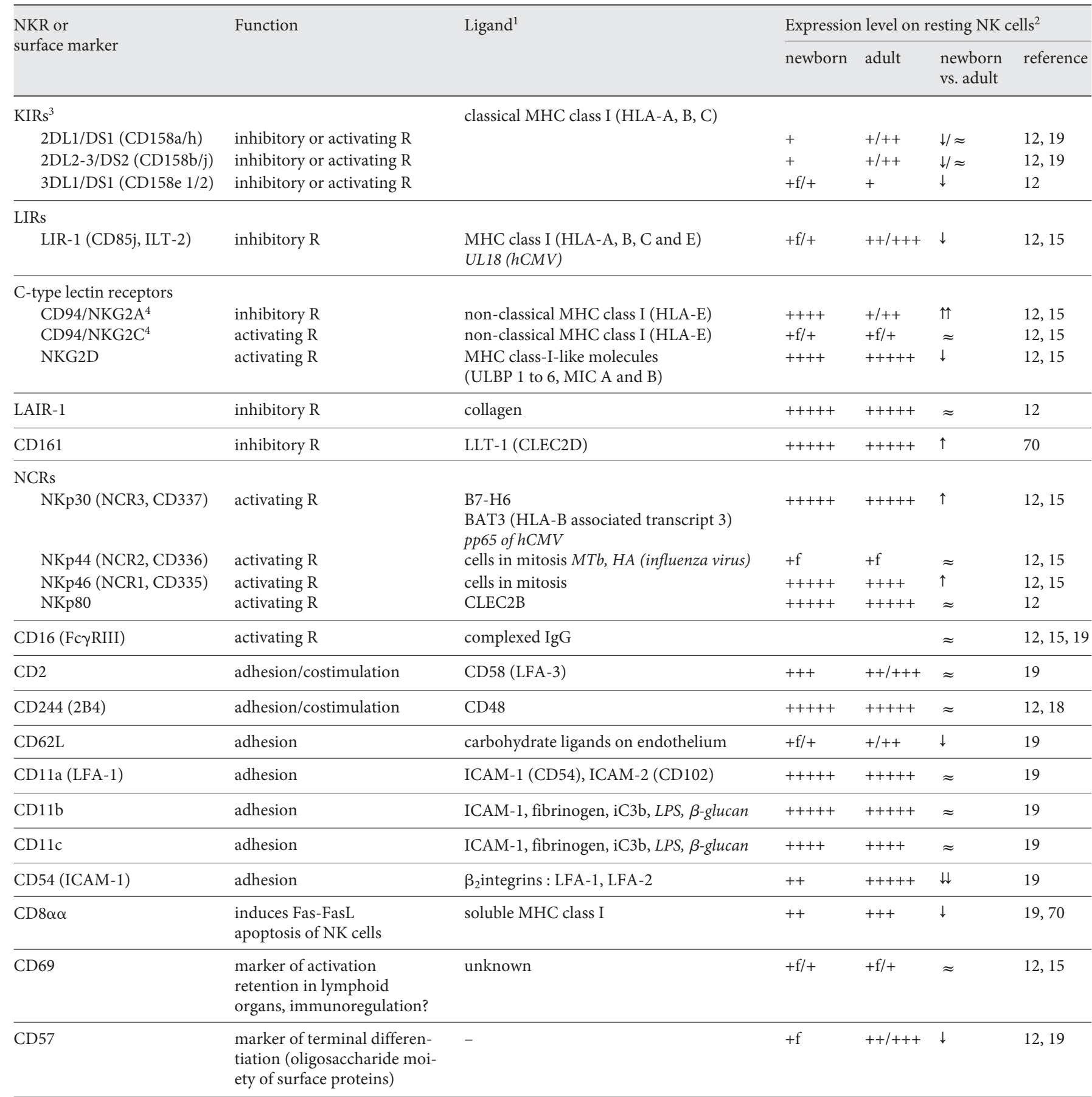

MHC = Major histocompatibility complex; HLA = human leukocyte antigen; ILT-2 = immunoglobulin-like transcript 2; MIC = MHC class 1 chain-related molecule; ULBP = UL16-binding protein; LAIR = leukocyteassociated immunoglobulin-like receptor; LLT-1 = lectin-like transcript 1; NCRs = natural cytotoxicity receptors; CLEC2B and CLEC2D = C-type lectin domain family 2 members $\mathrm{B}$ or $\mathrm{D}$; $\mathrm{HA}=$ hemagglutinin; ICAM = intercellular adhesion molecule; LFA = lymphocyte function-associated antigen.
${ }^{1}$ Microbial ligands are indicated in italics, others are self-ligands, either constitutively expressed or induced/released by stressed/infected/tumoral cells. ${ }^{2}+++++=\geq 90 \%$ of NK cells; $++++=70-90 \% ;+++=50-70 \% ;++=$ $30-50 \% ;+=10-30 \% ;+\mathrm{f}<10 \% .{ }^{3}$ KIRs are characterized by 2 (KIR2D) or 3 (KIR3D) extracellular Ig domains. In addition, they have either short (S) or long (L) intracytoplasmic tails which transduce activating or inhibitory signals. ${ }^{4}$ The proportion of NK cells expressing CD94 does not vary [19], suggesting that the NKG2 isoform is preferentially associated with variation in age. 
in adults [19, 21]. Decreased number of cytoplasmic granules, poor degranulation ability (i.e. low expression of CD107c, a marker of degranulation) [12] and impaired release of lytic factors have been revealed in CB NK cells, along with variable levels of perforin and granzyme contents $[19,22]$. Surface expression of Fas-ligand or tumor necrosis factor-related apoptosis-inducing ligand is comparable to adults [19]. The ability of CB NK cells to perform ADCC has been reported to be similar or reduced as compared to adult cells, although the expression of the FcyRIII (CD16) was normal [12, 20].

Adhesion between NK and target cells is a prerequisite for cytolysis to proceed. Studies have shown either normal binding of neonatal NK cells to virus-infected cells [20] or diminished binding to K562 cells as compared to adult NK cells [23]. The expression of the $\beta_{2}$-integrin lymphocyte function-associated antigen 1 (CD11a/CD18 heterodimer), playing a central role in tight adhesion as well as in polarization of cytolytic granules toward the immunological synapses [24] is reported to be normal on neonatal NK cells while other adhesins are diminished $[19,20]$. Whether these differences could result in adhesion defects still needs to be addressed. Defective cytotoxic capacity of neonatal NK cells may also result from poor quality of signaling through NK receptors (NKRs) as it is the case for other receptors [6]. However, this has not been investigated to date.

Interestingly, cytokines able to activate NK cells, like interleukin (IL)-2, IL-12, IL-15 and IFNs, are able to rescue cytotoxic defects in vitro by increasing adhesion molecules, perforin/granzyme contents and the level of granule exocytosis, allowing to reconstitute cytotoxic capacity to adult levels if sufficient amounts of cytokines are present $[12,25,26]$. This was the case in one study where IFN- $\alpha$ produced during in vitro infection with herpes simplex virus restores cytotoxic capacity of CB NK cells to adult levels [27]. The magnitude of cytotoxicity restoration will depend on the amounts of activating cytokines, and sufficient levels may not be found in newborns. Indeed, the capacity to produce IL-15, IL-12 and IFN- $\gamma$ in response to pathogens is dampened in early life $[6$, $7,28]$.

\section{IFN- $\gamma$ Production}

Another important function of NK cells relates to the production of cytokines which have been shown to modulate developing immune responses. Studies have mainly focused on IFN- $\gamma$ production, which has recently been shown to be presynthesized and stored in cytosolic granules (different from those containing cytolytic enzymes) to be rapidly released upon activation [29]. CB NK cells do not spontaneously produce IFN- $\gamma$, while the low level of this cytokine is released in vitro by adult cells [30]. Strong stimulation with phorbol ester and ionomycin activated a similar proportion of NK cells purified from $\mathrm{CB}$ and adult blood to produce IFN- $\gamma$ production [19], although the amount of IFN- $\gamma$ finally released by neonatal cells was lower [30]. IL-12, the canonical inducer of IFN$\gamma$, induced similar levels of IFN- $\gamma$ mRNA and protein in cord and adult NK cells [30], while when combined with IL-18, it boosted a still higher release of IFN- $\gamma$ by CB NK cells (by both CD56 $6^{\text {bright }}$ and CD56 ${ }^{\text {dim }}$ subsets) as compared to adult blood NK cells [12, 31].

\section{NK Cell Response to Infections Acquired in Early Life}

The data gathered on neonatal NK cells from healthy newborns seem to indicate that they present inherent defects more prominent at the level of their cytotoxic activity. In addition, it has been reported that soluble factors present in CB like prostaglandins and soluble human leukocyte antigen-G $[32,33]$, or cells such as $\mathrm{CD} 4^{+} \mathrm{CD} 25^{\text {high }}$ regulatory $\mathrm{T}$ cells more numerous in neonates, may contribute to limit NK cell functions [34, 35]. In addition, CB NK cells have been shown to be more prone to spontaneous apoptosis than their adult counterparts, despite their lower expression of Fas [36]. All these features should limit the ability of neonatal NK cells to fight infectious diseases due to intracellular pathogens. We review below what is known on $\mathrm{NK}$ cell responses to various infections.

\section{Viral Infections}

NK cells play a crucial role in the resolution of most viral infections, as evidenced by increased susceptibility when NK cell numbers are lacking prior to infection [37]. Humans genetically deficient in NK cells are particularly susceptible to herpesviruses [cytomegalovirus (CMV), Epstein-Barr virus (EBV), herpes simplex virus], varicella zoster virus infection, papillomaviruses, as well as to viral infections of the respiratory tract $[37,38]$, with severe and life-threatening recurrent infections in early life.

Severe acute respiratory infections with influenza virus or respiratory syncytial virus or severe varicella in the first years of life are associated with reduced levels of circulating NK cells [39-42]. Whether this relates to relocalization of cells in the periphery or to apoptosis is not known. However, influenza virus has recently been shown to infect NK cells and induce their apoptosis [43]. NK cell blood levels are also slightly decreased in human 
immunodeficiency virus (HIV)-infected infants as compared to uninfected ones. Both NK subsets are diminished. The drop in CD56 $6^{\text {bright }}$, but not CD56 ${ }^{\mathrm{dim}}$, NK cells seems to be related to a higher viral load and lower $\mathrm{CD} 4^{+}$ T-cell counts [44-46]. On the contrary, children undergoing active but asymptomatic CMV infection (excreting CMV DNA in urine and saliva) or chronic/latent infections with CMV or EBV do not present alterations in NK cell proportions $[47,48]$.

Viruses are known to induce modifications of the repertoire of NKRs. NK cell-specific triggering surface molecule (NKp)46 plays a critical function in the eradication of influenza virus [38] and its expression is increased in adults suffering from influenza [45]. At odds, its expression does not vary during severe influenza in children [41]. Pediatric CMV infection is associated, as in adults, with expansion of $\mathrm{CD} 94 / \mathrm{NKG}_{2} \mathrm{C}^{+} \mathrm{NK}$ cells. This is particularly prominent in children with viral excretion [47]. Meanwhile, although coexpression of the inhibitory receptor LIR-1 (known to bind the viral-encoded protein UL18) increases on CD94/NKG2C ${ }^{+}$cells, the expression of CD94/NKG2A is not modified [47]. These data suggest that $\mathrm{CD} 94 / \mathrm{NKG}_{2} \mathrm{C}^{+} \mathrm{NK}$ cells may participate in the early control of acute infection, and activating signals delivered by CD94/NKG2C may be later dampened by the acquisition of LIR-1. In contrast to what happens in CMV infection, NKG2A and some inhibitory KIRs are, or tend to be, increased in HIV-infected children [46]. This shift in the NKR repertoire, by enhancing inhibitory signals, could contribute to limit NK function and favor persistence of the virus. In line with this, NK degranulation seems to be suboptimal in HIV-infected children, as indicated by the lower expression of CD107 [46]. However, strangely, disease progression assessed by lowering of $\mathrm{CD}^{+} \mathrm{T}$-cell counts is associated with increased expression of activating receptors NKG2C and NKp46 [46].

An appealing role of NK cells in HIV infection concerns its potential to limit perinatal transmission of HIV from the infected mother to the newborn. NK cells have been shown to inhibit in vitro HIV replication in infected cells by producing large amounts of CC chemokine ligand (CCL)3, CCL4 and CCL5 that inhibit CC chemokine receptor-5-dependent entry of HIV into target cells [49]. Interestingly, the suppressive effect of neonatal NK cells was greater than that of adult cells [50]. Strongly supporting a protective role of NK cells in vertical transmission of HIV, a recent study shows that uninfected neonates from HIV-infected mothers display a higher proportion of NK cells that produce IFN- $\gamma$ in the presence of HIV peptides than infected infants from HIV-infected mothers [51]. This is the first report of an in utero 'sensitization' of NK cells by the mother. The underlying mechanism is not known.

In adults, EBV primo infection, causing infectious mononucleosis, is accompanied by higher circulating IFN- $\gamma$ levels and increased NK cell activity [52]. On the contrary, EBV-seropositive children display lower plasma IFN- $\gamma$ levels than seronegative ones, which is associated with reduced ability to produce IFN- $\gamma$ production by NK cells from infected infants [48]. Coinfection of these young children with CMV still decreases IFN- $\gamma$ levels. The reason of the difference between adults and young children is not known. However, it might contribute to the fact that children, contrary to adults, generally have asymptomatic primary EBV infection. Indeed, symptomatic mononucleosis is related to overproduction of inflammatory cytokines [52]. Recent findings of K. Bendjela et al. [pers. commun.] show that blood NK cells from respiratory syncytial virus-infected infants also displayed a reduced capacity to produce IFN- $\gamma$, compared with controls.

\section{Bacterial Infections}

NK cells also play a role in the control of bacterial infections, as indicated by the association of recurrent bacterial otitis media and sinusitis in young children with NK cell genetic defects [37]. However, information on NK cells in children suffering from bacterial infections is scarce. NK cells of infants experiencing bacterial infection during the first year of life, due to either group B Streptococcus, Staphylococcus aureus, Serratia or Escherichia coli, present an activated phenotype [53], whereas neonates undergoing early neonatal sepsis display strongly reduced NK cell cytotoxicity as compared to healthy neonates, although the number of NK cells was not really affected [54].

The importance of NK cells in controlling Mycobacterium tuberculosis ( $\mathrm{MTb}$ ) infection is still debated. Data suggest that NK cells might even have a detrimental role by inhibiting protective immunity [38]. The observation that many people have repeatedly negative tuberculin skin tests and remain healthy despite extensive exposition to the risk of infection suggests that the innate immune response in some individuals controls the infection [55]. Moreover, NK cells from patients presenting active disease exhibit impaired cytotoxicity [56], supporting the involvement of NK cells in the control of disease progression. NK cells in tuberculosis (TB) are mainly activated through NKp46 and NKG2D. Their beneficial effect relies on their ability to kill MTb-infected monocytes as 
well as to release IFN- $\gamma$ that sustains a protective $\mathrm{CD} 8^{+}$ T-cell response. They also favor the development of protective Th1 response by eliminating MTb-specific expanding regulatory $\mathrm{T}$ cells $[38,55]$. In children, particularly before 2 years of age, MTb infection progresses to severe disease more frequently and rapidly than in adults. The risk of disease progression decreases during childhood [57]. NK cell response in TB has not been studied in children, but we can speculate that the constitutively lower NKG2D expression (table 1), NK cytotoxic capacity and the ability to produce IFN- $\gamma$ in early life might contribute to a higher susceptibility of infants to TB. It would also be interesting to have information on the capacity to produce IL-22 in early life, as a subset of NK cells have recently been shown to produce IL-22 that indirectly limits in vitro intracellular growth of MTb [58].

\section{Protozoal Infections}

In adults, NK cells appear to be essential in controlling infections with intracellular protozoan, including malaria, toxoplasmosis, leishmaniasis and trypanosomiasis, during the early phase of the immune response [for a review, see ref. 59]. Except for malaria in which NK-mediated killing of infected red blood cells likely significantly contributes to protection, NK cell effector function in protozoan infections is rather cytokine mediated, with a major contribution of NK-derived IFN- $\gamma$ in early resistance. NK cells may be directly activated by parasite molecules like the lipophosphoglycan of leishmania interacting with Toll-like receptor 2 [60] or by yet unidentified molecules on red blood cells infected with Plasmodium $[59,61]$. However, activation of NK cells through contactdependent signals and cytokines released by monocytes and dendritic cells (mainly IL-12) or $\mathrm{CD}^{+} \mathrm{T}$ cells (IL-2) seems to prevail upon NKR-mediated activation $[4,59]$.

Again, few data are available on the role of NK cells in early life towards protozoans. In children with clinical malaria due to Plasmodium falciparum, a positive correlation has been observed between the degree of parasitemia and NK cell cytotoxic capacity, while NK cells are activated to produce higher levels of granzyme A and B as well as IFN- $\gamma[62,63]$. These data suggest that NK cells might be an essential component of innate protective immunity in early life. However, another study indicates that $\gamma \delta \mathrm{T}$ cells were predominant over NK cells in rapidly producing IFN- $\gamma$ in response to infected red blood cells [64]. This study, performed with children 5-14 years old, does not preclude a predominant role of NK cells in neonates as IFN- $\gamma$ providers, since $\gamma 9 \delta 2 \mathrm{~T}$-cell levels are strikingly less frequent at birth than after [65].
Human congenital infection can represent an interesting model of acute infection to investigate NK cells in early life. Our group has addressed the possibility that fetal NK cells play a role in the generation of the early cellular response during congenital infection. We previously described for the first time that fetuses were able to develop mature $\mathrm{CD}^{+}$T-lymphocyte responses in response to congenital infection with Trypanosoma cruzi, the protozoa agent of Chagas disease in South America [66], indicating that neonatal immune defects are not absolute. To investigate the mechanisms underlying the capacity of this intracellular pathogen to overcome fetal immune immaturity, we have studied the phenotype and activity of CB NK cells in such newborns [16]. We found that they displayed a reduced proportion of circulating CD56 $6^{\text {bright }} \mathrm{NK}$ cells, suggesting NK cells may have been recruited to secondary lymphoid organs. The remaining CD56 $6^{\text {bright }} \mathrm{NK}$ cells exhibited a defective ability to produce IFN- $\gamma$ in response to cytokines as compared with cells from uninfected newborns. In addition, CD56 ${ }^{\mathrm{dim}}$ NK cells from congenitally infected newborns stimulated with cytokines have a decreased capacity to release granzyme B, a defect associated with a reduced surface expression of activating NKRs (NKp30, NKp46 and NKG2D), as compared with uninfected newborns, while the expression of the inhibitory receptors NKG2A and LIR-1 remained similar. Thus, NK cell responses appear to be reduced at birth after congenital transmission of $T$. cruzi. To clarify whether this impaired NK cell response is a physiological result of their previous in utero activation triggered by congenital infection, or whether live $T$. cruzi present in infected fetuses have inhibited the NK cell response (which could represent a way for the parasite to improve its survival in the host), we have studied the effect of the parasite on CB NK cells from healthy newborns in vitro. We have observed that T. cruzi rapidly triggers, in a dose-dependent way, IFN- $\gamma$ production by both CD56 ${ }^{\text {bright }}$ and CD56 ${ }^{\mathrm{dim}}$ subsets of NK cells (fig. 1a). IFN- $\gamma$ induction is also found at the mRNA level (fig. 1b). IFN- $\gamma$ release was strongly enhanced in the presence of low doses of IL-15 [16]. Activation of neonatal NK cells by the parasite is also evidenced by upregulation of surface expression of CD54 (intercellular adhesion molecule 1) and CD69, and by downregulation of CD62L. However, T. cruzi alone exerted only a small direct activation of NK cells, and we demonstrated the need for the presence of monocytes, suggesting that the participation of accessory cells is required [unpubl. data]. In conclusion, our work suggests that neonatal NK cells are fully functional to respond to congenital infection.

J Innate Immun 2011;3:280-288 


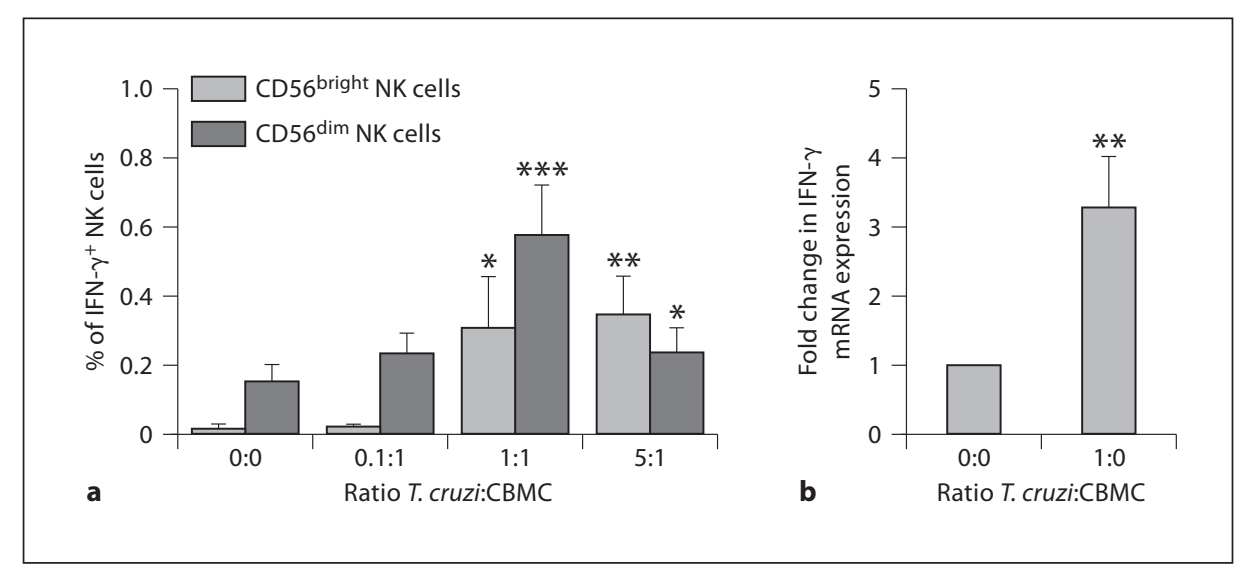

Fig. 1. IFN- $\gamma$ production by neonatal NK cells in response to $T$. cruzi. CB mononuclear cells (CBMC) were incubated for $24 \mathrm{~h}$ with T. cruzi live trypomastigotes at different parasite to cell ratios. Intracellular IFN- $\gamma$ was then detected by flow cytometry in CD3 ${ }^{-}$ CD56 $6^{\text {bright }}$ or CD56 ${ }^{\text {dim }} \mathrm{NK}$ cells (a, $\mathrm{n}=12$ samples), and IFN- $\gamma$ transcripts were measured by quantitative RT-PCR in CB mono-

\section{Concluding Remarks}

Though they are more numerous in blood, neonatal NK cells display some inherent qualitative defects contributing to the immaturity of the neonatal immune system. Such immaturity is probably essential to avoid deleterious overproduction of inflammatory cytokines, susceptible to provoke brain damages [67], when the newborn suddenly comes into contact with an overwhelming amount of (commensal) microorganisms during the first days of life. The cost of this immaturity in early life is an increased susceptibility to infectious diseases.

The modifications of circulating levels of NK cells observed during pediatric infections, their ability to produce IFN- $\gamma$ and undergo modifications of the NKR repertoire at the encounter with pathogens argue for their engagement in early life in the immune response in infectious diseases. Nevertheless, information is currently too limited and sparse to assess to which extent these NK cell responses really contribute to the control of infections, either vertically transmitted or acquired in infancy.

To answer such questions, some main points deserve major consideration and benefit of investigations, such as (1) the real ability of NK cells from infected newborns and children to produce cytokines in response to pathogens, to lyse infected target cells (and not only K562 cells) and to home into lymph nodes or peripheral tissues, compared to that of adult NK cells from infected individuals; nuclear cells. IFN- $\gamma$ mRNA levels were calculated using the $2^{\Delta \Delta C T}$ method, using GAPDH as calibrator and non-stimulated cells as reference (b, $\mathrm{n}=7$ samples). Results are expressed as the mean \pm SEM. ${ }^{*} \mathrm{p}<0.05,{ }^{* *} \mathrm{p}<0.01,{ }^{* * *} \mathrm{p}<0.001$, statistical comparison with the absence of parasites (Wilcoxon signed-rank test).

(2) the role of maternally transmitted antibodies in ADCC by NK cells against infectious agents, a topic poorly studied to date; (3) the role of long-term exposure to pathogens in early life (like infections with herpesviruses) in shaping the NKR repertoire, in 'arming' NK cells and in generating memory-like NK cells, concepts which have recently emerged from experimental studies [68, 69].

\section{Acknowledgments}

We thank the staff of the obstetric department of the Erasme Hospital (ULB, Brussels, Belgium) for the collection of umbilical $\mathrm{CB}$ samples with the informed consent of the mothers and in agreement with the ULB ethical committee guidelines. Our data mentioned in this review have been obtained by funding from the Fond National de la Recherche Scientifique (grants 3461505F and 1.5.284.08F), the Centre de Recherche Interuniversitaire en Vaccinologie sponsored by the Region Wallonne and Glaxo-SmithKline Biologicals (Rixensart, Belgium), the Conseil Interuniversitaire de la Communauté Française de Belgique, the Fonds Emile Defay (ULB) and the Fondation Van Buuren (ULB). 


\section{References}

$>1$ Jondal M, Spine C, Targan S: Human spontaneous killer cells selective for tumour-derived target cells. Nature 1978;272:62-64.

$>2$ Bendelac A: Innate-like lymphocytes. Curr Opin Immunol 2006;18:517-518.

$\checkmark 3$ Newman KC, Riley EM: Whatever turns you on: accessory-cell-dependent activation of NK cells by pathogens. Nat Rev Immunol 2007;7:279-291.

-4 Bihl F, Pecheur J, Breart B, Poupon G, Cazareth J, et al: Primed antigen-specific CD4+ T cells are required for $\mathrm{NK}$ cell activation in vivo upon Leishmania major infection. J Immunol 2010;185:2174-2181.

$>5$ Vivier E, Tomasello E, Baratin M, Walzer T, Ugolini S: Functions of natural killer cells. Nat Immunol 2008;9:503-510.

-6 Nguyen M, Leuridan E, Zhang T, De Wit D, Willems F, et al: Acquisition of adult-like TLR4 and TLR9 responses during the first year of life. PLoS One 2010;5:e10407.

$>7$ Levy O: Innate immunity of the newborn: basic mechanisms and clinical correlates. Nat Rev Immunol 2007;7:379-390.

$>8$ Marchant A, Goldman M: T cell-mediated immune responses in human newborns: ready to learn? Clin Exp Immunol 2005;141: $10-18$.

$>9$ Perez A, Gurbindo MD, Resino S, Aguaron A, Munoz-Fernandez MA: NK cell increase in neonates from the preterm to the full-term period of gestation. Neonatology 2007;92: 158-163.

$>10$ Raes M, Alliet P, Gillis P, Zimmermann A, Kortleven J, et al: Lymphocyte subpopulations in healthy newborn infants: comparison of cord blood values with values five days after birth. J Pediatr 1993;123:465-467.

-11 de Vries E, Bruin-Versteeg S, Comans-Bitter WM, de Groot R, Hop WC, et al: Neonatal blood lymphocyte subpopulations: a different perspective when using absolute counts. Biol Neonate 2000;77:230-235.

12 Garff-Tavernier M, Beziat V, Decocq J, Siguret V, Gandjbakhch F, et al: Human NK cells display major phenotypic and functional changes over the life span. Aging Cell 2010;9:527-535.

$\checkmark 13$ Kim JP, Lee YH, Lee YA, Kim YD: A comparison of the kinetics of nucleated cells and CD34+ cells in neonatal peripheral blood and cord blood. Biol Blood Marrow Transplant 2007; 13:478-485.

-14 Tabiasco J, Rabot M, Aguerre-Girr M, El Costa H, Berrebi A, et al: Human decidual NK cells: unique phenotype and functional properties - a review. Placenta 2006;27(suppl A):S34-S39.

-15 Sundstrom Y, Nilsson C, Lilja G, Karre K, Troye-Blomberg $\mathrm{M}$, et al: The expression of human natural killer cell receptors in early life. Scand J Immunol 2007;66:335-344.
16 Hermann E, Alonso-Vega C, Berthe A, Truyens $\mathrm{C}$, Flores A, et al: Human congenital infection with Trypanosoma cruzi induces phenotypic and functional modifications of cord blood NK cells. Pediatr Res 2006;60: 38-43.

17 Braud VM, Allan DS, O’Callaghan CA, Soderstrom K, D'Andrea A, et al: HLA-E binds to natural killer cell receptors CD94/NKG2A, B and C. Nature 1998;391:795-799.

18 Kim EO, Kim TJ, Kim N, Kim ST, Kumar V, et al: Homotypic cell-to-cell crosstalk among human natural killer cells reveals differential and overlapping roles of 2B4 and CD2. J Biol Chem 2010;285:41755-41764.

19 Dalle JH, Menezes J, Wagner E, Blagdon M, Champagne J, et al: Characterization of cord blood natural killer cells: implications for transplantation and neonatal infections. Pediatr Res 2005;57:649-655.

20 Kohl S, Sigouroudinia M, Engleman EG: Adhesion defects of antibody-mediated target cell binding of neonatal natural killer cells. Pediatr Res 1999;46:755-759.

21 Uksila J, Lassila O, Hirvonen T, Toivanen P: Development of natural killer cell function in the human fetus. J Immunol 1983;130: 153-156.

22 Wang Y, Xu H, Zheng X, Wei H, Sun R, et al: High expression of NKG2A/CD94 and low expression of granzyme $\mathrm{B}$ are associated with reduced cord blood NK cell activity. Cell Mol Immunol 2007;4:377-382.

23 Nair MP, Schwartz SA, Menon M: Association of decreased natural and antibody-dependent cellular cytotoxicity and production of natural killer cytotoxic factor and interferon in neonates. Cell Immunol 1985;94: 159-171.

24 Gross CC, Brzostowski JA, Liu D, Long EO: Tethering of intercellular adhesion molecule on target cells is required for LFA-1-dependent NK cell adhesion and granule polarization. J Immunol 2010;185:2918-2926.

25 Bonnema JD, Rivlin KA, Ting AT, Schoon RA, Abraham RT, et al: Cytokine-enhanced NK cell-mediated cytotoxicity. Positive modulatory effects of IL-2 and IL-12 on stimulus-dependent granule exocytosis. J Immunol 1994;152:2098-2104.

-26 Nguyen QH, Roberts RL, Ank BJ, Lin SJ, Thomas EK, et al: Interleukin (IL)-15 enhances antibody-dependent cellular cytotoxicity and natural killer activity in neonatal cells. Cell Immunol 1998;185:83-92.

27 Hayward A, Laszlo M, Vafai A: Human newborn natural killer cell responses to activation by monoclonal antibodies. Effect of culture with herpes simplex virus. J Immunol 1989;142:1139-1143.
28 Qian JX, Lee SM, Suen Y, Knoppel E, van de Ven C, et al: Decreased interleukin-15 from activated cord versus adult peripheral blood mononuclear cells and the effect of interleukin-15 in upregulating antitumor immune activity and cytokine production in cord blood. Blood 1997;90:3106-3117.

29 Reefman E, Kay JG, Wood SM, Offenhauser $\mathrm{C}$, Brown DL, et al: Cytokine secretion is distinct from secretion of cytotoxic granules in NK cells. J Immunol 2010;184:4852-4862.

30 Lau AS, Sigaroudinia M, Yeung MC, Kohl S: Interleukin-12 induces interferon-gamma expression and natural killer cytotoxicity in cord blood mononuclear cells. Pediatr Res 1996;39:150-155.

-31 Nomura A, Takada H, Jin CH, Tanaka T, Ohga S, et al: Functional analyses of cord blood natural killer cells and T cells: a distinctive interleukin-18 response. Exp Hematol 2001;29:1169-1176.

32 Webb BJ, Bochan MR, Montel A, Padilla LM, Brahmi Z: The lack of NK cytotoxicity associated with fresh HUCB may be due to the presence of soluble HLA in the serum. Cell Immunol 1994;159:246-261.

33 Joshi PC, Zhou X, Cuchens M, Jones Q: Prostaglandin E2 suppressed IL-15-mediated human NK cell function through down-regulation of common gamma-chain. J Immunol 2001;166:885-891.

-34 Nakamura K, Miki M, Mizoguchi Y, Karakawa S, Sato T, et al: Deficiency of regulatory T cells in children with autoimmune neutropenia. Br J Haematol 2009; 145:642-647.

-35 Trzonkowski P, Szmit E, Mysliwska J, Dobyszuk A, Mysliwski A: CD4+CD25+ T regulatory cells inhibit cytotoxic activity of $\mathrm{T}$ CD8+ and NK lymphocytes in the direct cell-to-cell interaction. Clin Immunol 2004; 112:258-267.

36 Lin SJ, Cheng PJ, Huang YJ, Kuo ML: Evaluation of cytotoxic function and apoptosis in interleukin (IL)-12/IL-15-treated umbilical cord or adult peripheral blood natural killer cells by a propidium-iodide based flow cytometry. Pediatr Allergy Immunol 2004;15: 79-85.

-37 Orange JS: Human natural killer cell deficiencies and susceptibility to infection. $\mathrm{Mi}$ crobes Infect 2002;4:1545-1558.

38 Culley FJ: Natural killer cells in infection and inflammation of the lung. Immunology 2009;128:151-163.

39 Ribeiro LZ, Tripp RA, Rossi LM, Palma PV, Yokosawa J, et al: Serum mannose-binding lectin levels are linked with respiratory syncytial virus (RSV) disease. J Clin Immunol 2008;28:166-173.

40 de Weerd W, Twilhaar WN, Kimpen JL: T cell subset analysis in peripheral blood of children with RSV bronchiolitis. Scand J Infect Dis 1998;30:77-80. 
-41 Heltzer ML, Coffin SE, Maurer K, Bagashev $\mathrm{A}$, Zhang Z, et al: Immune dysregulation in severe influenza. J Leukoc Biol 2009;85: 1036-1043.

-42 Vossen MTM, Biezeveld MH, de Jong MD, Gent MR, Baars PA, et al: Absence of circulating natural killer and primed CD8(+) cells in life-threatening varicella. J Infect Dis 2005;191:198-206.

-43 Mao H, Tu W, Qin G, Law HK, Sia SF, et al: Influenza virus directly infects human natural killer cells and induces cell apoptosis. J Virol 2009;83:9215-9222.

- 44 Azzoni L, Rutstein RM, Chehimi J, Farabaugh MA, Nowmos A, et al: Dendritic and natural killer cell subsets associated with stable or declining CD4+ cell counts in treated HIV-1-infected children. J Infect Dis 2005; 191:1451-1459.

-45 Fu GF, Chen X, Hao S, Zhao JL, Hu HY, et al: Differences in natural killer cell quantification and receptor profile expression in HIV-1 infected Chinese children. Cell Immunol 2010;265:37-43.

46 Ballan WM, Vu BAN, Long BR, Loo CP, Michaelsson J, et al: Natural killer cells in perinatally HIV-1-infected children exhibit less degranulation compared to HIV-1-exposed uninfected children and their expression of KIR2DL3, NKG2C, and NKp46 correlates with disease severity. J Immunol 2007;179: 3362-3370.

-47 Monsivais-Urenda A, Noyola-Cherpitel D, Hernandez-Salinas A, Garcia-Sepulveda C, Romo N, et al: Influence of human cytomegalovirus infection on the NK cell receptor repertoire in children. Eur J Immunol 2010; 40:1418-1427.

48 Saghafian-Hedengren S, Sundstrom Y, Sohlberg E, Nilsson C, Linde A, et al: Herpesvirus seropositivity in childhood associates with decreased monocyte-induced NK cell IFNgamma production. J Immunol 2009;182: 2511-2517.

49 Fauci AS, Mavilio D, Kottilil S: NK cells in HIV infection: paradigm for protection or targets for ambush. Nat Rev Immunol 2005; 5:835-843.
0 Bernstein HB, Kinter AL, Jackson R, Fauci AS: Neonatal natural killer cells produce chemokines and suppress HIV replication in vitro. AIDS Res Hum Retroviruses 2004;20: 1189-1195.

51 Tiemessen CT, Shalekoff S, Meddows-Taylor S, Schramm DB, Papathanasopoulos MA, et al: Cutting edge: unusual NK cell responses to HIV-1 peptides are associated with protection against maternal-infant transmission of HIV-1. J Immunol 2009;182:5914-5918.

52 Ohga S, Nomura A, Takada H, Hara T: Immunological aspects of Epstein-Barr virus infection. Crit Rev Oncol Hematol 2002;44: 203-215.

53 Hodge G, Hodge S, Han P, Haslam R: Multiple leucocyte activation markers to detect neonatal infection. Clin Exp Immunol 2004; 135:125-129.

54 el Sameea ER, Metwally SS, Mashhour E, el Bendary A, Hassan AM, et al: Evaluation of natural killer cells as diagnostic markers of early onset neonatal sepsis: comparison with C-reactive protein and interleukin-8. Egypt I Immunol 2004;11:91-102.

55 Vankayalapati R, Barnes PF: Innate and adaptive immune responses to human $\mathrm{Myco}$ bacterium tuberculosis infection. Tuberculosis (Edinb) 2009;89(suppl 1):S77-S80.

56 Maertzdorf J, Repsilber D, Parida SK, Stanley K, Roberts T, et al: Human gene expression profiles of susceptibility and resistance in tuberculosis. Genes Immun 2010, Epub ahead of print.

57 Swaminathan S, Rekha B: Pediatric tuberculosis: global overview and challenges. Clin Infect Dis 2010;50(suppl 3):S184-S194.

58 Dhiman R, Indramohan M, Barnes PF, Nayak RC, Paidipally P, et al: IL-22 produced by human NK cells inhibits growth of Mycobacterium tuberculosis by enhancing phagolysosomal fusion. J Immunol 2009; 183: 6639-6645.

59 Korbel DS, Finney OC, Riley EM: Natural killer cells and innate immunity to protozoan pathogens. Int J Parasitol 2004;34:15171528.

-60 Becker I, Salaiza N, Aguirre M, Delgado J, Carrillo-Carrasco N, et al: Leishmania lipophosphoglycan (LPG) activates NK cells through toll-like receptor-2. Mol Biochem Parasitol 2003;130:65-74.
61 Roetynck S, Baratin M, Johansson S, Lemmers C, Vivier E, et al: Natural killer cells and malaria. Immunol Rev 2006;214:251263.

62 Ojo-Amaize EA, Salimonu LS, Williams AI, Akinwolere OA, Shabo R, et al: Positive correlation between degree of parasitemia, interferon titers, and natural killer cell activity in Plasmodium falciparum-infected children. J Immunol 1981;127:2296-2300.

63 Hermsen CC, Konijnenberg Y, Mulder L, Loe C, van Deuren M, et al: Circulating concentrations of soluble granzyme A and B increase during natural and experimental Plasmodium falciparum infections. Clin Exp Immunol 2003;132:467-472.

64 D'Ombrain MC, Hansen DS, Simpson KM Schofield L: Gammadelta-T cells expressing NK receptors predominate over NK cells and conventional T cells in the innate IFN-gamma response to Plasmodium falciparum malaria. Eur J Immunol 2007;37:1864-1873.

65 Parker CM, Groh V, Band H, Porcelli SA Morita C, et al: Evidence for extrathymic changes in the $\mathrm{T}$ cell receptor gamma/delta repertoire. J Exp Med 1990;171:1597-1612.

66 Hermann E, Truyens C, Alonso-Vega C, Even J, Rodriguez P, et al: Human fetuses are able to mount an adultlike CD8 T-cell response. Blood 2002;100:2153-2158.

67 Yuan TM, Sun Y, Zhan CY, Yu HM: Intrauterine infection/inflammation and perinatal brain damage: role of glial cells and Tolllike receptor signaling. J Neuroimmunol 2010;229:16-25.

68 Sun JC, Beilke JN, Lanier LL: Immune memory redefined: characterizing the longevity of natural killer cells. Immunol Rev 2010; 236:83-94

69 Orange JS: Latent herpesviruses: aligning human and murine NK cells. Blood 2010; 115:4321-4322.

70 Peoples JD, Cheung S, Nesin M, Lin H, Tatad AM, et al: Neonatal cord blood subsets and cytokine response to bacterial antigens. Am J Perinatol 2009;26:647-657. 